\title{
Experimental Study and Optimization in Modified Air Abrasive Jet Machining on Nickel-233 Alloy Using MCDM Techniques
}

\author{
S. Rajendra Prasad ${ }^{1}$, Dr. K.Ravindranath ${ }^{2}$, Dr.M.L.S. Devakumar ${ }^{3}$ \\ ${ }^{1}$ Research scholar, Department of Mechanical Engineering, JNTUA, Ananthapuramu. E-mail: sidda- \\ gunta.raja@gmail.com \\ ${ }^{2}$ Professor, Department of Mechanical Engineering, SVCET, CHITTOOR \\ ${ }^{3}$ Professor, Department of Mechanical Engineering, JNTUA, Ananthapuramu.
}

\begin{abstract}
This paper demonstrates the new multi criterion decision making (MCDM) techniques were used, i.e. the weighted aggregated sum and product assessment (WASPAS) technique. This involves the modified air abrasive jet machining (MAAJM) of Nickel 233 alloy using carbide coated nozzle in $3 \mathrm{~mm}$ dia with three responses are considered as against the process variables of injecting pressure, standoff distance, and abrasive mesh size. The optimal combination of MAAJM process parameter for simultaneous minimization of taper angle, surface roughness and maximization of MRR are injecting pressure of $0.686 \mathrm{MPa}$, standoff distance $9 \mathrm{~mm}$ and abrasive mesh size $400 \mu \mathrm{m}$ with 3 diameter carbide coated nozzle. The optimal results attained with the WASPAS technique demonstrated to good relation with another technique multi objective optimization rational analysis (MOORA).
\end{abstract}

Keywords: MOORA, Nickel 233 alloy, Process parameters, WASPAS

\section{Introduction}

In the present world there is an expansive assortment of materials/parts likes $\mathrm{Al}, \mathrm{Mg}$, steel, etc expanding step by step. So as to finish merchandise with required properties, it is particularly troublesome with ordinary machining forms. By and large, it is very hard to process the hard materials with customary machines when contrasted and bendable materials and furthermore the machining of hard material is tedious, high handling cost, less precise, increasingly shot of hardware disappointment, poor surface completion. All the above elements lead to grow new machines and machining procedures with which we can accomplish required properties easily of activity, less time utilization, great surface completion, with vast material expulsion rate, more prominent instrument life, less power devouring, effortlessly of generation and furthermore machining of complex structures. The vast majority of the offbeat machining arrangements are accessible to process complex structures, with various material qualities (electrically, synthetically, flexibly, weakness) to suit anticipated applications. They are ultrasonic machining (USM), electrical release machining(EDM), electro synthetic machining(ECM), laser beam machining(LBM), plasma arc machining(PAM), water jet machining(WJM), abrasive water jet machining(AWJM), air abrasive jet machining (AAJM), and so forth.,

Air abrasive jet machining is an effect machining technique that evacuates material by coordinating a high speed stream of rough particles onto a work piece. The procedure vary from sand impact in three essential ways: (i) the principle reason of sand impact is to clean work piece surface, while AAJM is utilized to cut material; (ii) the grating molecule measurement utilized in sand impact is greater than that of the rough fine particles utilized in AAJM; (iii) high speed stream of particles is practical among AAJM.

AJM machine that are at present financially accessible and utilized by the specialists utilize an essential structure, through which the rough particles are impacted always on to the work piece Produced opening as for nozzle measurement estimate.

Broad literature on Experimental and optimization models is available.

However, most of the studies are interrelated to machining operation. Someworks dealing with parametric analysis in AJM process have been investigated by various investigators. Madhu et al [1] conducted an experiment on modified nozzle shape internal threading system on parameters such as nozzle Dia, grain size and SOD on CFRP material. . The investigational result showed presence of excellent surface finish on CFRP material from the newly considered nozzle with inside thread. Skyhook Leary et al [2] proposed a novel approach, rotating mask arrangement fixed in AJMM on SOD and Time changing parameters are used to conduct experiments. It improves the footprint shape on the target material by using of rotary mask. Xiao Sui et al [3] demonstrated surface texturing of mechanical seals in machining process consideration of AFR and SOD on RBSC, SU304 and carbon graphite. It is analyzed parameters hence found that Carbon graphite has great material removal rate, and SUS304 could have low surface irregularity after machining on least AFR and SOD. Nouhia et al implemented shadow mask for direct marks on glass material with different parameters and observed that least amounting of frosting in decreases SOD and particle size [4].Bharat Chandra et al. conducted experiments on glass material and analyzed different responses such as MRR and $\mathrm{Ra}$ in machining parameters pressure, SOD, and Abrasive size. The outcome is analyzed by ANOVA and GRA. It is accomplished with performance characteristics of the AJM development such as MRR and surface roughness [5]. Jagannatha \& Hiremath [6] conducted experiments and analyzed the process parameters on SOD, Feed, and Air temperature using of ANOVA. In that they found Air is more dominant parameter among the other parameters to get min roughness and max MRR The paper presented by Pham 
Huu Loc et al. [7] indicated the use of N-BK7 glass material to perform machining operations by considering process parameters pressure, angle and abrasive dimension using of copper nozzle on the consequential analyze by Taguchi. The values obtained are observed that the polishing time, the air pressure, and the impact angle drastically affect the polished Ra. inside this article Adel et al [8] in their article demonstrated Multi-objective optimization Fuzzy-Evolutionary Approach in validated on other process. In that they are concluded that a well wellspread Pareto front line for the measured MOOUC problems. Nanda\& Mishra et al.used as a modified experiment and also parametric optimization in multiple regression and PSO on different parameters. The experimental optimal progression parametric setting be pressure of 5 $\mathrm{Kgf} / \mathrm{cm} 2$, nozzle tip distance of $8 \mathrm{~mm}$ and grain size of $260 \mu \mathrm{m}$ for achieve the finest responses, and the outcome are experimentally validate finally[9].Abdelnasser \& Elkaseer et al Here the author has considered parameters pressure, SOD, nozzle dia, grain size and impact angle on glass material and the results obtained were analyzed using ANN and GA and concluded that the process produces to form the MRR more exactly, mostly to found affairs among practical machining parameters and experimentally calculated MRR and achieve a maximum inaccuracy $5.3 \%$. The result shows that the GA is a successful method to see the optimal solutions for maximum MRR amid an inaccuracy of $8.4 \%$. [10]

Shankar Chakra borty et.al [11] investigated the applicability of weighted aggregated sum product assessment (WASPAS) method is explore used for parametric optimization of five nontraditional machining processes. It is accomplished that WASPAS method can be deploy as a helpful tool for both single response and multi response optimization of the NTM processes. It is also experimental that this method is reasonably strong.

Kim et al. [12] used magnetic abrasive particles in modified Abrasive Jet Machining process for machining of curved tubes internal machining process. In this modifications resulted in increased machining efficiency. Balasubramanian et al. [13,14, and 15] conducted experimental work on conventional AJM to remove burrs, edges and improving of hole dimensions in machining. In their investigations they found that Stand-off Distance as a main effecting parameter to produce a finished product with accuracy through ANOVA analyze. Jain et al. [16] implemented a modified AFM for cylindrical work piece. This work mainly to find out the stresses developed during the flow of materials by using finite element method. They also estimated MRR and surface finish in abrasive flow machining process. MuJu [17] modified setup to decrease work material temperature by using liquid nitrogen in setup. In these conditions they found that MRR improved as per modifications. Zhang et al. [18] modified setup to add more cleaning period known as Micro abrasive intermittent jet machining. In which they found depth and diameter of the machined hole are mainly influenced proportional to pressure, on/off valve, and Stand-offDistance. Park et al. [19] introduced masking operation in micro-AJM machining of glass. They considered general process parameters for making a hole and line type grooves. It resulted in excellent positive change of the masking process over without masking process. Barletta et al [20, 21, and 22] conducted experiments on Circular tubes polishing which is very critical to perform in conventional AJM process with good finishing and stipulated time. To overcome this above problem they introduced a novel technology for finishing of internal parts. They developed setup namely Fluidized Bed assisted Abrasive Jet Machining (FB-AJM).

Jianxin et.al [23] worked on gradient ceramic composite coat applied to nozzle material for erosion wear resistance. They used $\mathrm{SiC}$ abrasives $50-150 \mu \mathrm{m}$ at $0.4 \mathrm{MPa}$ pressure. This modification compared to conventional ceramic nozzles results in improvement of nozzle wear resistance.

Khodke P.M et al. [24], Investigated on optical microscopy which has indicated that the abrasive particles used in abrasive jet machining have sharp edges with the shapes similar to pyramid or cone. Besides, microscopic examination of cross section of work samples eroded by AJM shows that, for brittle materials, removal of material is due to intersection and spreading of clacks produced by neighbor colliding particles on target plane. Mathematical model has been developed based on the above observations for forecasting the removal of material in abrasive jet machining process. The analytical model also suggests the vital value of mass flow rate which has been validated experimentally. As well as, the influence of mass flow rate and velocity of abrasive particles on MMR is described briefly.

Sehgal K.B et al. [25], Studied on Abrasive jet machining, which is a micromachining practice, where material is detached from the work piece by the erosion effect of a elevated speed stream of abrasive particles carried in a gas(air) medium, which are coming from a nozzle. This process is primarily used to machine hard and brittle materials like, glass, ceramics, semi-conductors electronic devices hast-alloy \& Nitra-alloy, etc. Also this study illustrates the result of a variety of process parameters and optimizes them to achieve efficiency \& economy in this micro- machining method. This process is extremely helpful in deburring radius forming and finishing of hard and brittle materials.

Bharat Chandra Routara et al. [26] discussed the relevance of the Taguchi method to optimize the machining variables for machining of glass work-pieces in abrasive jet machining (AJM) for individual responses such as material removal rate and surface roughness. Besides, a multi-response performance characteristic was utilized for optimization of process variables (parameters) with adoption of grey relational analysis. The machining variables (parameters) are selected as pressure, nozzle-tipdistance, abrasive grain size where as the response variables selected as material removal rate (MRR) and surface roughness $(\mathrm{Ra})$. The results from verification runs indicated that the determined most favorable combination of machining variables (parameters) improved the performance of the machining process.

Manikyam Reddy Sargam et al. [27] were carried out 
experimental Analysis and Optimization of Process Variables in Machining of RCFRP by AJM. In this investigation work presents the effects of process parameters on material removal rate in AJM during machining of Rayon based CFRP composite. Abrasive jet machining (AJM) removes material through the action of concentrated beam of abrasive jet subjected at the target surface the resulting erosion can be used for cutting, drilling and debarring etc. For this experimental investigation type of abrasive particles commonly used is silicon carbide (Sic). Here the process parameters are air pressure, abrasive flow rate, nozzle diameter and stand of distance. This experimental work includes designing and analyzing of response surface. From this research the overall performance of variables on metal removal rate (MRR) of work piece with statistically investigated by Response surface methodology (RSM) method was analyzed and optimized were compared with ANOVA for optimal value. Best parameters found for Larger is better MRR are: Pressure $\left(6 \mathrm{~kg} / \mathrm{cm}^{2}\right)$, Abrasive Flow Rate $(4.5 \mathrm{gm} / \mathrm{sec})$, Nozzle diameter $(5 \mathrm{~mm})$ and Stand of Distance $(8 \mathrm{~mm})$. The nozzle diameter is the most significant factor which affect the MRR and then next significant factors follows are Pressure, AFR and SOD. And Predicted S value (0.00761) and Regression square value (95.85\%). It is observed that performance of characteristics of AJM was improved by using this method.

Thomas beck et al. [28], made an effort to find out feasibility of Laser drilling in gas turbine blades. Drilling applications represent about the author $5 \%$ of the industrial laser materials processing applications. Cooling holes in gas turbines for aircrafts as well as for power plants are one of the major applications. The development of productivity has led to several drilling strategies with respect to laser sources (thermal drilling and ablation drilling), the beam handling, beam distribution, and handling of the work piece, all of which contribute to the overall efficiency of the process and a high productivity. They represented the successful improvement and execution of a combination of laser systems with different pulse timings for drilling complex 3D geometries.

Multi Attribute Decision Making Using Simple Additive Weighting and Weighted Product in Investment Yeni Melia et al. [29], Investigated that investment always have two sides, namely return and risks, the more return offered the higher risk to be borne by investors. Return on investment that is stock dividends and capital gains are less predictable, in which investors had to do an analysis or judgment shares in order to gain an advantage. Decision objective need a system that could help in the decision. The selection of share is expected to facilitate investors in determining based on sector investment that will rank. It happens by cleaning the analysis on key aspects of stock, the evaluation criterion that you later then used as the criterion in the rank procedure and weighting on the respective the evaluation criterion. Multi attribute decision making (MADM) is a method of the choice to set up an alternative best of a number of alternatives based on a number of definite criteria. One method the MADM used in research is SAW (simple additive weighting model) and WPM (weighted product) model. The result from the this study by using the Simple Additive Weight (SAW) and Weighted Product (WP) showed that high value is 0,79965 and 0,18434 .

Shankar Chakraborty et al. [30] explored applications of WASPAS method as a multi-criteria decision-making tool. The weighted aggregated sum product assessment (WASPAS) method is a exclusive combination of weighted sum model (WSM) and weighted product model (WPM). Because of its numerical simplicity and capability to provide more exact results as compared to WSM and WPM methods, it is now being widely accepted as an efficient decision-making tool. In this work, its applicability is validated using five real time manufacturing related problems while selecting (a) a flexible manufacturing system, (b) a machine in a flexible manufacturing cell, (c) an automated guided vehicle, (d) an automated inspection system, and (e) an industrial robot. It is observed that for all these five problems, WASPAS method provides quite satisfactory results. The optimal $\lambda$ values for each of the considered problem are evaluated and the effects of varying $\lambda$ values on ranking of the candidate alternatives in WASPAS method are also analyzed.

Zavadskas et al. [31] evaluated effectiveness of computer-aided multiple criteria decision support system as well as accuracy of decisions based on an application of a proper MCDM method. They observed that WSM and WPM methods can produce different ranking results. Accordingly, methodology for assessment of accuracy of methods, based on initial criteria values, was developed. It was proposed to apply a joint method of the litters, i.e. WASPAS (Weighted Aggregates Sum Product Assessment), to increase the ranking accurateness. Accuracy of estimation applying WSM, WPM and WASPAS was evaluated. It was estimated that exactness applying WASPAS increases up to 1.3 times as compared to WPM and up to 1.6 times as compared to WSM. As a result, it was ascertained that the proposed joint method enables to increase the ranking accuracy. Methodology for optimization of weighted aggregated function was proposed, that enables to reach the highest accuracy of judgment. An example of application of methodology was presented. Relative importance of alternatives within the particular probability was deliberated. Bobby et al. [32], prepared fact sheet which covers nozzle description, recommended use for common nozzle types, and orifice sizing for agricultural and turf sprayers. Appropriate selection of a nozzle type and size is necessary for correct and accurate pesticide application. The nozzle is a major factor in determining the amount of spray applied to an area, uniformity of application, coverage obtained on the target surface, and amount of potential drift.Ching-Been Yang et al. [33] experimented on single and multiobjective optimization of Inconel 718 nickel-based super alloy in the wire electrical discharge machining. Inconel 718 is extensively used in high-temperature environments, high-performance aircraft, and hypersonic missile weapon systems; however, it is very complex to machine using conventional techniques. This study implemented an L9 Taguchi orthogonal array for the analysis of wire electrical discharge machining parameters when used for the machining of Inconel 718. Their main aim was to determine 
the optimal combination of parameters to minimize surface roughness while maximizing the material removal rate. The Taguchi method is extensively applied in mechanical engineering with the goal of identifying the optimal pair of processing parameters as they pertain to single quality characteristics. Unfortunately, Taguchi analysis often leads to conflicting results when seeking to rectify multiple objectives. To resolve this issue, this study employed gray relational analysis in conjunction with Taguchi method to obtain the optimal combination of parameters to deal specially with multiple quality objectives. For the double objectives of surface roughness and material removal rate, the optimal combination of parameters derived using gray relational analysis resulted in a mean surface roughness of $2.75 \mu \mathrm{m}$. In L9 orthogonal array experiments, run 1 produced the best gray relational grade with mean surface roughness of $2.80 \mu \mathrm{m}$, representing an enhancement of $1.8 \%$. The material removal rate achieved after the application of gray relational analysis was $0.00190 \mathrm{~g} / \mathrm{s}$, whereas the $\mathrm{L} 9$ experiment attained a material removal rate of $0.00123 \mathrm{~g} / \mathrm{s}$, representing a progress of $54.5 \%$.

Atul Shukla et al. [34] reviewed the applications of TOPSIS Algorithm on various Manufacturing Processes. Different Manufacturing Processes Optimized by Technique for Order Preference by Similarity to Ideal Solution (TOPSIS) Algorithm is presented in this review. The main focus of this review is on the optimization of the different manufacturing processes that have been optimized by TOPSIS method. The machining processes that have been considered in this work are Milling, Drilling, Turning, Electric Discharge Machining, Abrasive Jet Machining, Micro Machining, and other advanced types of machining process. The review work on manufacturing processes, on such a large scale was not performed previously by considering different processes at a time on TOPSIS method, and hence, this review work prepared for the future information at one place for the subsequent researchers, in order to determine their way of research on TOPSIS Algorithm. Srikanth et al [35] fabricated AJM setup and conducting on glass material with different parameters and observed that Kerfs characteristics.

A number of researchers consist of be current exposed on AJM in experimentally and to optimization of process parameters on brittle materials, hard materials are very less comprehensive.

The goal of this paper is focused on parametric optimization used as a multi-objective optimization technique as a MCDM methods of hard material as NICKEL 233 alloy. The methods has been developed and successfully used by Chakra borty et al [11] in the non-traditional machining process. The methodology developed can handle even MCDM approaches efficiently combined with design of experiment and minimization of experimental runs.

\section{Methodology}

The procedural steps being involved in solving multi objective optimization problems is presented below as illustrated Chakra borty et al [11].

Step 1. Set the initial decision matrix
Step 2. Normalization of the decision matrix by using the following equations:

$$
\begin{aligned}
\mathrm{X}_{\mathrm{ij}} & =\frac{x_{i j}}{\max _{i} x_{i j}} \text { for beneficial criteria, } \\
\mathrm{Xij} & =\frac{\min _{i} x_{i j}}{x_{i j}} \text { for non-beneficial criteria, }
\end{aligned}
$$

Xijis normalized value of $x i j$. Its application primary require expansion of a decision matrix, $X=\left[x_{\mathrm{ij}}\right]_{\mathrm{m} \times \mathrm{n}}$ where $\mathrm{x}_{\mathrm{ij}}$ is the performance of the $i^{\text {th }}$ alternative with respect to the $j^{\text {th }}$ condition, $m$ is the number of candidate alternatives and $n$ is the number of appraisal criterion.

Step 3. The first decisive factor of optimality, i.e. decisive factor of a mean weighted achievement is parallel to WSM method. The total relative importance of the ith alternative, based on weighted sum method (WSM), is calculated as follows:

$$
\boldsymbol{Q}_{i}^{(\mathbf{1})}=\sum_{\mathrm{j}=\mathbf{1}}^{\mathrm{n}} \mathbf{X}_{\mathrm{ij}} \mathbf{w}_{\mathrm{j}}
$$

Here $w j$ is weights (relative importance or significance) of the $j^{\text {th }}$ criterion. The weight of a particular criterion can be determined using analytic hierarchy process or entropy method.

Step 4 . The total relative importance of the $i^{\text {th }}$ alternative, based on weighted product method (WPM), is calculated as follows:

$$
\mathrm{Q}_{\mathrm{i}}^{(2)}=\prod_{\mathbf{j}=\mathbf{1}}^{\mathbf{n}} \mathbf{X}_{\mathbf{i j}}{ }^{\mathbf{w j}}
$$

A joint generalized criterion of weighted aggregation of additive and multiplicative methods is then proposed as follows:

$\boldsymbol{Q}_{\boldsymbol{i}}=0.5 \boldsymbol{Q}^{(\mathbf{1})}+0.5 \boldsymbol{Q}^{(\mathbf{2})}=0.5 \sum_{\mathbf{j}=\mathbf{1}}^{\mathbf{n}} \mathbf{X}_{\mathrm{ij}} \mathbf{w}_{\mathbf{j}}+0.5 \prod_{\mathbf{j}=\mathbf{1}}^{\mathrm{n}} \mathbf{X}_{\mathrm{ij}}{ }^{\mathbf{w j}}(5)$

Step 5.In order to have increased ranking accuracy and effectiveness of the decision-making process, in WASPAS method, a more generalized equation for determining the total relative importance of the $i^{\text {th }}$ alternative is developed and further applied as below:

$$
\begin{gathered}
\boldsymbol{Q}_{\boldsymbol{i}}=\lambda \boldsymbol{Q}^{(\mathbf{1})}+(1-\lambda) \boldsymbol{Q}^{(\mathbf{2})}=\lambda \sum_{\mathrm{j}=\mathbf{1}}^{\mathrm{n}} \mathbf{X}_{\mathrm{ij}} \mathbf{w}_{\mathrm{j}}+ \\
(1-\lambda) \prod_{\mathrm{j}=\mathbf{1}}^{\mathrm{n}} \mathbf{X}_{\mathrm{ij}}^{\mathbf{w j}}, \lambda=0,0.1 \ldots \ldots \ldots 1
\end{gathered}
$$

Here we arrange to develop the best possible parametric combination for a Abrasive Jet Machining process in the direction of control its improved machining presentation, numerous experimental runs (trials) are frequently conducted based on Box-Behnken design is an experimental plan and it would be always popular that the most good parametric setting for the considered MAAJM process be capable of carry on selected from between the presented experimental trials.

MAAJM processes has a few responses based on which its machining performance is assess. Some of these responses (material removal rate) are beneficial in nature requiring higher values. On the further tender, a number of responses (surface roughness and taper cut) are nonbeneficial wherever lower values are all the time favored. Depending upon the finish necessities and type of the products manufactured, the method engineer must assign right of way or relative importance to each of the measured responses. Sometimes, the help of analytic hierarchy process is sorted for determining the priority weights 
of the responses. For a multi-response optimization problem, the apply engineer is use to allocate like importance to all the measured response and can afterward be valid WASPAS method for a given $\lambda$ value whereas all together optimizing every one the responses.

Here, the measured responses are optimized all at a point and a single parametric arrangement is find which in the direction of to be able of is set for achieve the best show of the MAAJM process. Going on the further hand, in single response optimization, all the responses are optimized independently and diverse personality parametric setting is attained for all of the responses. In this case, the method engineer must assign maximum meaning of one to a demanding response which wants to maximize/minimize, and assign minimum importance of zero to the continuing responses. Then apply WASPAS technique, the most favorable parametric settings can be attain for an exacting value of $Q$.

\section{Experimental procedure:}

\subsection{Material:}

A Nickel 233 [36] alloy was selected as the work material. Nickel 233 alloys be a commercially clean formed nickel alloy to exhibit outstanding oxidization resistance and high electrical as well as thermal conductivities. On the other hand, the alloy is subjected to bury coarse embrittlement by means of sulfur compound above $315^{\circ} \mathrm{C}$.

In this material chemical and mechanical properties are given tables (1) and (2).

\section{Chemical Composition}

The chemical composition nickel 233 alloy is outline inside the following table (1).

\section{Tab. 1 Chemical properties}

\begin{tabular}{|c|c|}
\hline Element & Content (\%) \\
\hline Manganese, $\mathrm{Mn}$ & $0.2-0.3$ \\
\hline Silicon, $\mathrm{Si}$ & $0.05-0.1$ \\
\hline Iron. $\mathrm{Fe}$ & $0.75-0.1$ \\
\hline Copper, $\mathrm{Cu}$ & $0.5-0.1$ \\
\hline Carbon, $\mathrm{C}$ & $0.5-0.1$ \\
\hline Magnesium, $\mathrm{Mg}$ & $0.01-0.1$ \\
\hline Sulfur, $\mathrm{S}$ & 0.008 \\
\hline Titanium, $\mathrm{Ti}$ & 0.005 \\
\hline Nickel, $\mathrm{Ni}$ & Balance \\
\hline
\end{tabular}

\section{Mechanical Properties}

The following table (2) shows the physical properties of nickel 233 alloy.

\section{Tab. 2 Mechanical Properties}

\begin{tabular}{|l|l|c|}
\hline \multicolumn{1}{|c|}{ Properties } & \multicolumn{1}{|c|}{ Metric } & Units \\
\hline Density & 8.89 & $\mathrm{~g} / \mathrm{cm} 3$ \\
\hline Melting point & 1443 & ${ }^{\circ} \mathrm{C}$ \\
\hline Tensile strength (annealed) & $650-880$ & $\mathrm{MPa}$ \\
\hline Yield strength (annealed) & $350-550$ & $\mathrm{MPa}$ \\
\hline $\begin{array}{l}\text { Elongation at break (anne- } \\
\text { aled prior to test) }\end{array}$ & $8-25$ & $\%$ \\
\hline $\begin{array}{l}\text { Thermal expansion co-effi- } \\
\text { cient }\end{array}$ & 10 & $\mu \mathrm{m} / \mathrm{m}^{\circ} \mathrm{C}$ \\
\hline Thermal conductivity & 25 & $\mathrm{~W} / \mathrm{mK}$ \\
\hline
\end{tabular}

\subsection{Machining Procedure:}

The experiments have been carried out on a modified AAJM shown in Fig (1). Fig 1 represents main modifications done on the work table which is rotatable and reciprocatable by induction motor and bevel gear mechanism for changing of Standoff distance. In this single stage air compressor is used for achieving required pressure for air jet and dual tube oil, water separator air filter is used for cleaning air. $3 \mathrm{~mm}$ size carbide coated nozzle is used in machining as shown in fig2. The different size $(300,400$, and 500) Al2O3 abrasive particles were used in machining as shown in fig 3 . Injecting pressure range of 0 $2 \mathrm{MPa}$ is used and worktable is rotated at constant speed of $100 \mathrm{rpm}$ which is measured by a Non contact type Tachometer was used. The dimension of the work piece selected is $100 \mathrm{~mm} \mathrm{X} 75 \mathrm{~mm} \mathrm{X} 1 \mathrm{~mm}$, which is as per work table dimensions are cut to size $50 \mathrm{~mm} \times 50 \mathrm{~mm} \times 1 \mathrm{~mm}$. Table 2 shows the chemical composition of the Nickel 233 alloy. Fig (3) shows the after machining of work pieces.

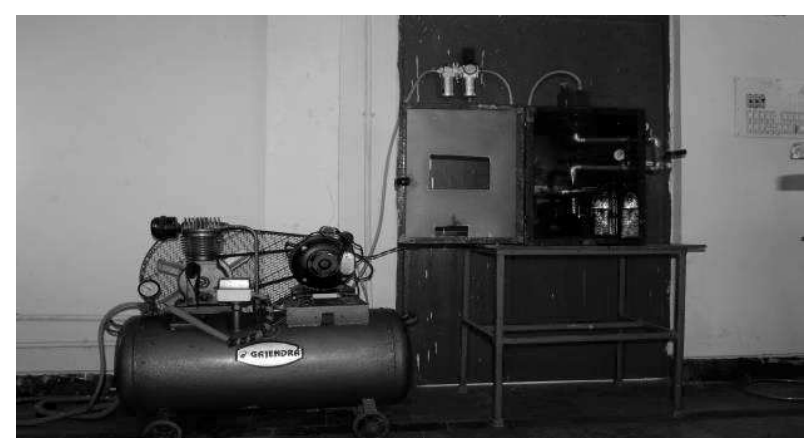

Fig. 1 Fabricated MAAJM Setup

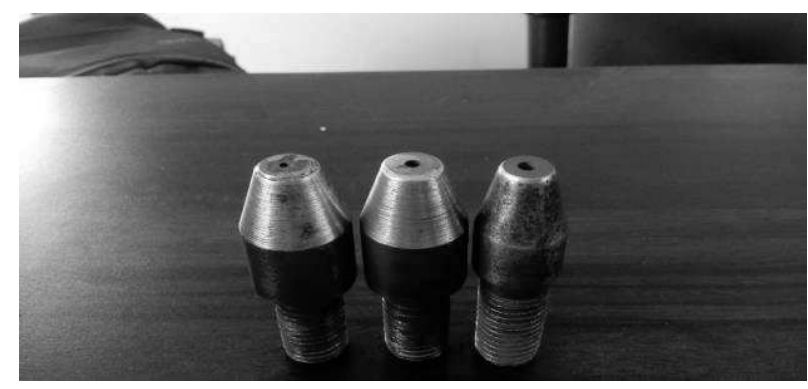

Fig. 2 Carbide coated nozzle in three different diameters

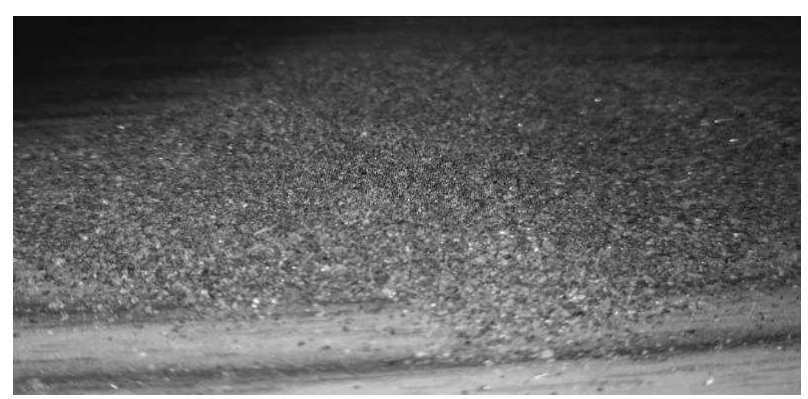

Fig. $3 \mathrm{Al}_{2} \mathrm{O}_{3}$ Abrasive particles

This total variation of parameters in this process was carried out according to the design of experiments (DOE) by considering the Box-Behnken design. The test specimen was drilled as per requirement of experimental work on MAAJM setup. 
In this paper mainly on three controllable parameters (injecting air pressure, standard of distance and abrasive mesh size) and three response variables (MRR, Ra, and
Ta), each factor has three levels shown in table 3 , and also designed table 4 Box-Behnken RSM coded values

Tab. 3 Input parameters with their coded value at different levels

\begin{tabular}{|c|c|c|c|c|c|}
\hline $\begin{array}{c}\text { S. } \\
\text { No }\end{array}$ & Input parameter & Units & Low level & Mid level & High level \\
\hline 1 & $\begin{array}{c}\text { Injecting Pres- } \\
\text { sure }\end{array}$ & $\mathrm{MPa}$ & 0.490 & 0.588 & 0.686 \\
\hline 2 & $\begin{array}{c}\text { Stand-off } \\
\text { distance }\end{array}$ & $\mathrm{mm}$ & 5 & 7 & 9 \\
\hline 3 & $\begin{array}{c}\text { Abrasive mesh } \\
\text { size }\end{array}$ & $\mu \mathrm{m}$ & 300 & 400 & 500 \\
\hline
\end{tabular}

Tab. 4 Box-Behnken RSM based coded experimental design matrix

\begin{tabular}{|c|c|c|c|}
\hline S. no. & Injecting Pressure & Stand-off distance & Abrasive mesh size \\
\hline 1 & -1 & -1 & 0 \\
\hline 2 & 1 & 0 & 1 \\
\hline 3 & 0 & 1 & -1 \\
\hline 4 & 0 & 1 & -1 \\
\hline 5 & 1 & 0 & 0 \\
\hline 6 & 1 & 1 & 0 \\
\hline 7 & -1 & 1 & 0 \\
\hline 8 & 0 & 0 & 0 \\
\hline 9 & 1 & -1 & -1 \\
\hline 10 & 0 & -1 & 1 \\
\hline 11 & -1 & 0 & -1 \\
\hline 12 & 0 & -1 & 0 \\
\hline 13 & -1 & 0 & 0 \\
\hline
\end{tabular}

\subsection{Measuring Instruments}

\section{Material removal rate (MRR) -}

The material removal rate can be described as the total amount of the removed material per unit time. The MRR is calculated by the equation given below

$\mathrm{MRR}=$ the weight of work piece before process - the weight of work piece after process / time

\section{Surface roughness (SR)}

Tester of surface roughness after any type of machining the part machine gets rough to the touch so it is a parameter to be calculated to secure the good quality of a product. When the surface is touched one can feel the coarseness of the surface and a rough surface is unwanted. Only a smooth surface is desired. A smooth surface is attained by keeping the best information or suitable information of the factors to be employed. Small force in the machined work piece or object can be reckoned by using Talysurf instrument.

\section{Taper angle measurement-}

The gadget Opton vision 60 is used to measure the taper angle. These instruments are applied to measure some factors (parameters) such as bigger radius (r1), smaller radius (r2) and the depth of the hole (h) by utilizing the given empirical relations the taper angle is measured.

$$
\alpha=\tan ^{-1}(r 1-r 2) / h
$$

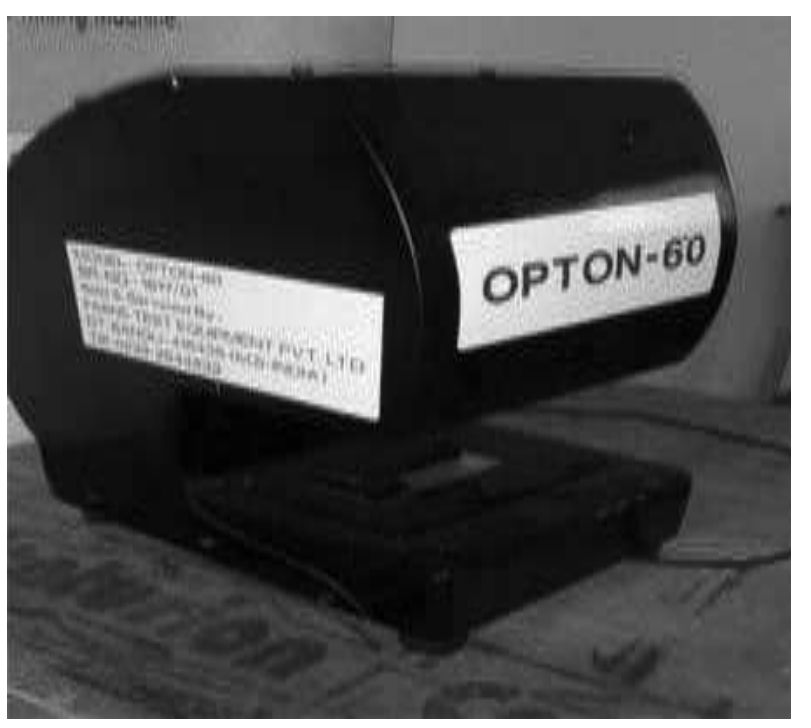

Fig. 5 Opton 60 Vision taper measurement 
Tab. 5 Experimental data using 100 RPM (rotary worktable)

\begin{tabular}{|c|c|c|c|c|c|c|c|}
\hline S. no & Hole no & $\begin{array}{c}\text { IP } \\
(\mathrm{MPa})\end{array}$ & $\begin{array}{c}\text { SOD } \\
(\mathrm{mm})\end{array}$ & $\begin{array}{c}\text { AMS } \\
(\mu \mathrm{m})\end{array}$ & $\begin{array}{c}\text { MRR } \\
(\mathrm{g} / \mathrm{sec})\end{array}$ & $\begin{array}{c}\text { Ra } \\
(\mu \mathrm{m})\end{array}$ & $\begin{array}{c}\text { Ta } \\
(\mathrm{rad})\end{array}$ \\
\hline 1 & 1 & 0.490 & 5 & 400 & 0.071 & 0.6893 & 22.43 \\
\hline 2 & 3 & 0.686 & 7 & 500 & 0.089 & 0.5400 & 20.20 \\
\hline 3 & 2 & 0.588 & 9 & 500 & 0.083 & 0.5950 & 19.06 \\
\hline 4 & 5 & 0.588 & 9 & 300 & 0.079 & 0.4500 & 22.01 \\
\hline 5 & 7 & 0.686 & 7 & 300 & 0.078 & 0.4275 & 20.79 \\
\hline 6 & 9 & 0.686 & 9 & 400 & 0.080 & 0.6044 & 20.45 \\
\hline 7 & 10 & 0.490 & 9 & 400 & 0.075 & 0.6725 & 22.74 \\
\hline 8 & 12 & 0.588 & 7 & 400 & 0.082 & 0.6700 & 22.50 \\
\hline 9 & 6 & 0.686 & 5 & 400 & 0.078 & 0.6170 & 20.57 \\
\hline 10 & 8 & 0.588 & 5 & 300 & 0.067 & 0.4925 & 19.86 \\
\hline 11 & 16 & 0.490 & 7 & 500 & 0.091 & 0.6950 & 21.98 \\
\hline 12 & 18 & 0.588 & 5 & 500 & 0.090 & 0.6275 & 20.96 \\
\hline 13 & 4 & 0.490 & 7 & 300 & 0.071 & 0.5000 & 22.98 \\
\hline 14 & 11 & 0.588 & 7 & 400 & 0.081 & 0.6325 & 22.87 \\
\hline 15 & 14 & 6 & 7 & 400 & 0.080 & 0.6325 & 22.76 \\
\hline
\end{tabular}

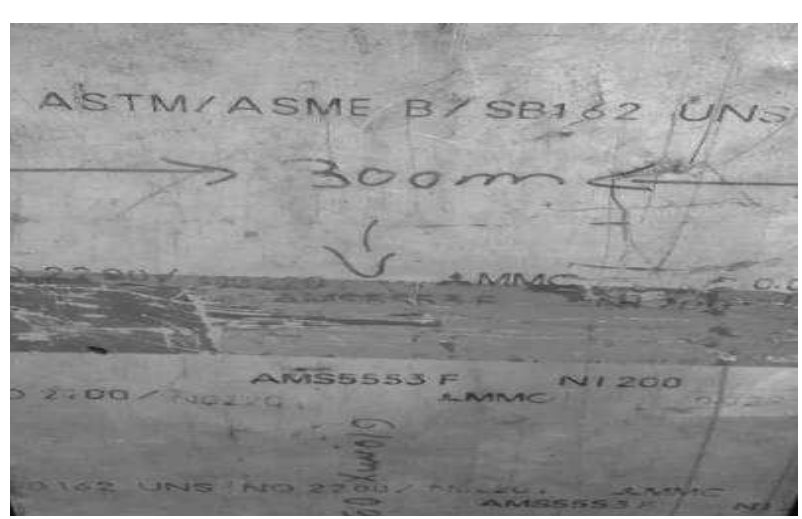

a)

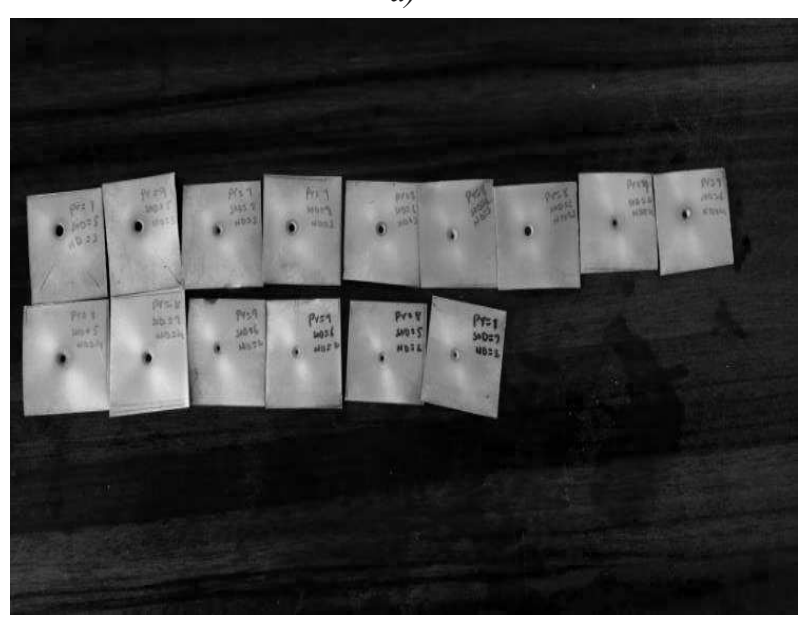

b)

Fig. 6 NICKEL 233 Alloy material (a) Before (b) After Machining
Fig. 6 a\&b shows that before and after machining of NICKEL 233 alloy material in MAAJM

\section{Results and discussion}

The objective of the present work is to optimize the machining parameters in modified air abrasive jet machining (MAAJM) operation using compared WASPAS and MOORA method for optimizing the multi-objectives. The most important measure in the compared WASPAS and MOORA method for analyzing experimental data is relative closeness. In this study, the relative closeness should have a maximum value to obtain optimum cutting conditions, according to the WASPAS method. Two categories of performance characteristics, i.e., minimization and maximization are selected in this study. To obtain optimal machining performance, the minimization characteristic for taper angle, surface roughness and maximization characteristics for $M R R$ have been taken. The results obtained from the experimental runs are shown in Tab. 5 . Tab. 6 shows data of relative closeness for taper angle, surface roughness and $M R R$.

The relative closeness is used to determine the optimum combination of machining parameters for minimizing taper angle, surface roughness and maximizing MRR. The maximum relative closeness indicates the minimum values of taper angle, surface roughness and maximum values of MRR and their values are injecting pressure of $0.686 \mathrm{MPa}$, standoff distance $9 \mathrm{~mm}$ and abrasive mesh size $400 \mu \mathrm{m}$ with 3 diameter carbide coated nozzle. This method is simple with less computational steps and also compared to MOORA method is exactly matching to the parameter combinations. 
Tab. 6 Normalized data using WASPAS

\begin{tabular}{|c|c|c|c|c|c|c|c|}
\hline $\begin{array}{c}\text { S. } \\
\text { No }\end{array}$ & MRR & Ra & Ta & Q1 & Q2 & Q & Rank \\
\hline 1 & 0.7802 & 0.6201 & 0.8497 & 0.75 & 0.7457 & 0.7478 & 15 \\
\hline 2 & 0.978 & 0.7916 & 0.9435 & 0.9043 & 0.9015 & 0.9029 & 2 \\
\hline 3 & 0.912 & 0.7184 & 1 & 0.8768 & 0.8697 & 0.8732 & 4 \\
\hline 4 & 0.8681 & 0.95 & 0.8659 & 0.8946 & 0.8948 & 0.8947 & 3 \\
\hline 5 & 0.8571 & 1 & 0.9167 & 0.9246 & 0.9234 & 0.924 & 1 \\
\hline 6 & 0.8791 & 0.7073 & 0.932 & 0.8394 & 0.8352 & 0.8373 & 7 \\
\hline 7 & 0.8241 & 0.6356 & 0.8381 & 0.7659 & 0.762 & 0.7639 & 14 \\
\hline 8 & 0.901 & 0.638 & 0.8471 & 0.7953 & 0.7886 & 0.7919 & 13 \\
\hline 9 & 0.8571 & 0.6928 & 0.9265 & 0.8254 & 0.8314 & 0.8284 & 8 \\
\hline 10 & 0.7362 & 0.868 & 0.9597 & 0.8546 & 0.8509 & 0.8527 & 6 \\
\hline 11 & 1 & 0.6151 & 0.8671 & 0.8274 & 0.8126 & 0.82 & 10 \\
\hline 12 & 0.989 & 0.6812 & 0.9093 & 0.8598 & 0.8506 & 0.8552 & 5 \\
\hline 13 & 0.7802 & 0.855 & 0.8294 & 0.8215 & 0.8225 & 0.8220 & 9 \\
\hline 14 & 0.8901 & 0.6758 & 0.8334 & 0.7997 & 0.7962 & 0.7979 & 11 \\
\hline 15 & 0.8791 & 0.6758 & 0.8374 & 0.7974 & 0.7942 & 0.7958 & 12 \\
\hline
\end{tabular}

For the purpose of validation, the same MAAJM process parameter selection problem is solved by using the MOORA method as one of the new MCDM technique. The computational details and step-by-step procedure of the MOORA method is explained in details in [37]. $Y i$ is the assessment value (composite score) are rankings are given in Table 7 .

Tab. 7 Normalized data using MOORA

\begin{tabular}{|c|c|c|c|c|c|}
\hline S no & MRR & Ra & Ta & Yi & Rank \\
\hline 1 & 0.2291 & 0.2994 & 0.2692 & -0.1130 & 15 \\
\hline 2 & 0.2872 & 0.2345 & 0.2424 & -0.0631 & 2 \\
\hline 3 & 0.2679 & 0.2498 & 0.2287 & -0.0701 & 4 \\
\hline 4 & 0.2550 & 0.1954 & 0.2641 & -0.0680 & 3 \\
\hline 5 & 0.2517 & 0.1857 & 0.2495 & -0.0611 & 1 \\
\hline 6 & 0.2582 & 0.2625 & 0.2454 & -0.0831 & 7 \\
\hline 7 & 0.2420 & 0.2921 & 0.2729 & -0.1075 & 14 \\
\hline 8 & 0.2646 & 0.2910 & 0.2700 & -0.0987 & 13 \\
\hline 9 & 0.2517 & 0.2680 & 0.2469 & -0.0876 & 8 \\
\hline 10 & 0.2162 & 0.2139 & 0.2383 & -0.0785 & 6 \\
\hline 11 & 0.2937 & 0.3019 & 0.2638 & -0.0905 & 10 \\
\hline 12 & 0.2905 & 0.2726 & 0.2515 & -0.0777 & 5 \\
\hline 13 & 0.2291 & 0.2172 & 0.2758 & -0.0878 & 9 \\
\hline 14 & 0.2614 & 0.2747 & 0.2745 & -0.0958 & 11 \\
\hline
\end{tabular}

The comparative analysis between the optimal parametric combinations observed experimentally and those attained using WASPAS and MOORA method for single response optimization of the MAAJM process.

\section{Conclusions}

In the present study compared WASPAS and MOORA method, a multi objective optimization methods, have been adopted to find the optimum combination of machining parameters such as injecting pressure, standoff distance and abrasive mesh size for simultaneous minimization of taper angle, surface roughness and maximization ofMRR while modified air abrasive jet machining Nickel 233 alloy.
- Equal weight factors are involved for all responses.

- $\quad$ The compared WASPAS and MOORA method is used to select the best combination of machining parameters in MAAJM operation. The alternatives are sorted in a ranking wise set with their relative closeness as 15-2-4-3-1-7-14-13-86-10-5-9-11-12.

- From the relative closeness values, it is evident that the machining parameter assigned as alternative 5 is the first choice, alternative 2 is the second choice and 1 is the last choice for the given application under given set of conditions. 
- The optimal combination of MAAJM process parameter for simultaneous minimization of taper angle, surface roughness and maximization of MRR are injecting pressure of $0.686 \mathrm{MPa}$, standoff distance $9 \mathrm{~mm}$ and abrasive mesh size $400 \mu \mathrm{m}$ with 3 diameter carbide coated nozzle.

- The compared to WASPAS and MOORA method consider weight criteria of each objective for a better and accurate evaluation of the alternatives.

- These methods have the advantage of utilizing simple computational steps for simultaneous optimization of multiple objectives.

\section{Acknowledgement}

The author(s) declare(s) that there is no conflict of interest regarding the publication of this paper.

\section{References}

[1] MADHU S, BALASUBRAMANIAN M. (2017). Influence of Nozzle Design and Process Parameters on Surface Roughness of CFRP Machined by Abrasive Jet Materials and Manufacturing,. Taylor \& Francis, Vol. 32, issue 9, 1011-1018.

[2] SOOKHAK LARI M.R. GHAZAVI A, PAPINI M. (2017). A rotating mask system for sculpting of three-dimensional features using abrasive jet micro-machining Elsevier Journal of Materials Processing Technology 243, 62-74.

[3] XIAO SU\& LIPING SHI, \& WEI HUANG \& XIAOLEI WANG. (2016).A multi-phase microabrasive jet machining technique for the surface texturing of mechanical seals Int $J$ Adv Manuf Techno 86:2047-2054

[4] NOUHIA A, SOOKHAK LARI M.R, SPELT J.K, PAPINI M. (2015).Implementation of a shadow mask for direct writing in abrasive jet micro-machining, Elsevier Journal of Materials Processing Technology, Volume 223, 232-239.

[5] ROUTARA B.C,NANDA, B.K., SAHOO, A.K., THATOI, D.N. AND NAYAK, B.B. (2011) Optimization of multiple performance characteristics in abrasive jet machining using grey relational analysis, Int. J. Manufacturing Technology and Management, Vol. 24, Nos. 1/2/3/4,pp.4-22.

[6] JAGANNATHA N, HIRE MATH S, SADA SHIRAPPA K (2012) Analysis and parametric optimization of Abrasive hot air jet machining for glass using taguchi method and utility concept, International Journal of Mechanical and Materials Engineering (IJMME), Vol. 7 No. 1, 9-15.

[7] PHAM HUU LOC, FANG-JUNG SHIOU, AND ZONG-RU YU Investigation of Optimal Air-Driving Fluid Jet Polishing Parameters for the Surface
Finish of N-BK7 Optical Glass ASME Vol. 135 / 011015-1.

[8] ADEL T. ABBAS,MOHAMED ALY,KARIM HAMZA Multiobjective Optimization Under Uncertainty in Advanced Abrasive Machining Processes Via a Fuzzy-Evolutionary Approach, ASME Vol. 138 / 071003-1.

[9] NANDA B.K, MISHRA A \& DHUPAL D. (2017).Fluidized bed abrasive jet machining (FBAJM) of K-99 alumina ceramic using Sic abrasives. Springer Int $J A d v$ Manuf Techno 90:36553672

[10] ABDELNASSER, AHMED ELKASEER (2016), Abrasive jet machining of glass: Experimental investigation with ANN modeling and genetic algorithm optimization" Taylor \& Francis Abdelnasser et al., Cogent Engineering 3: 1276513.

[11] SHANKAR CHAKRA BORTY, ORCHI BHATTACHARYYA, EDMUNDAS KAZIMIERAS ZAVADSKAS, JURGITA ANTUCHEVICIENE (2015)Application of WASPAS Method as an Optimization Tool in Non-traditional Machining Processes ISSN 1392-124X (print), ISSN 2335-884X (online) Information Technology And Control, , T. 44, Nr. 1.

[12] JEONG-DU KIM , YOUN-HEE KANG, YOUNG-HAN BAE, SU-WON LEE ( 1997), Development of a magnetic abrasive jet machining system for precision internal polishing of circular tubes, Journal of Materials Processing Technology 71 .384-393.

[13] BALASUBRAMANIAM R, KRISHNAN J, RAMAKRISHNAN N. (1999) an experimental study on the abrasive jet deburring of cross-drilled holes, Journal of Materials Processing Techno$\log y 91.178-182$.

[14] BALASUBRAMANIAM R, KRISHNAN J, RAMAKRISHNAN N. (2000), An empirical study on the generation of an edge radius in abrasive jet external deburring (AJED), Journal of Materials Processing Technology, Vol. 99,49-53.

[15] BALASUBRAMANIAM R, KRISHNAN J, RAMAKRISHNAN N. (1998), Investigation of AJM for deburring, Journal Volume 79, Issues 1$3,1.52-58$.

[16] RAJENDRA K. JAIN, VIJAY K. JAIN, P.M. DIXIT (1999) ,Modeling of material removal and surface roughness in abrasive flow machining process, International Journal of Machine Tools \& Manufacture 39.1903-1923

[17] MUJU M K, PATHAK A.K, (1988) Abrasive Jet Machining OF Glass at Low Temperature, Journal of Mechanical Working Technology, 17,325-332.

[18] LEI ZHANG, TSUNEMOTO KURIYAGAWA, YUYA YASUTOMI, Ji Zhao (2005)Investigation 
into micro abrasive intermittent jet machining, International Journal of Machine Tools \& Manufacture 45,873-879.

[19] DONG-SAM PARK , MYEONG-WOO CHO, HONGHEE LEE, WON-SEUNG CHO (2004) Micro-grooving of glass using micro-abrasive jet machining,. Journal of Materials Processing Technology, 146,234-240.

[20] MASSIMILIANO BARLETTA, VINCENZO TAGLIAFERRI (2006)Development of an abrasive jet machining system assisted by two fluidized beds for internal polishing of circular tubes. International Journal of Machine Tools \& Manufacture, 46, 271-283.

[21] BARLETTA M, CECCARELLI D, GUARINO S, TAGLIAFERRI V.(2007) Fluidized Bed Assisted Abrasive Jet Machining (FB-AJM): Precision Internal Finishing of Inconel 718 Components, Journal of Manufacturing Science and Engineering , Vol. 129 / 1045

[22] MASSIMILIANO BARLETTA, STEFANO GUARINO, GIANLUCA RUBINO, AND VINCENZO TAGLIAFERRI(2007) Progress in Fluidized Bed Assisted Abrasive Jet Machining (FB-Ajm): Internal Polishing Of Aluminum Tubes, Manufacture Volume,483-495.

[23] DENG JIANXIN, WU FENGFANG, ZHAO JINLONG (2007) Wear mechanisms of gradient ceramic nozzles in abrasive air-jet machining, International Journal of Machine Tools \& Manufacture 47.2031-2039

[24] P. M. KHODKE , D. J. TIDKE \& A. V. RAMARAO, (1996)An Analytical Model for Material Removal in Abrasive Jet Machining for Brittle Materials, Materials and Manufacturing Processes, 11:4, 535-554.

[25] K.B. SEHGAL, (2011), Study and Optimization of Process Parameters in Abrasive Jet Machining, Impulse Vol. 7 48-52.

[26] BHARAT CHANDRA ROUTARA, B.K. NANDA AND ASHOK KUMAR SAHOO,(2011) Optimization of multiple performance characteristics in abrasive jet machining using grey relational analysis, Int. J. Manufacturing Technology and Management, Vol. 24, Nos. 1/2/3/4, 4-22.

[27] SARGAM MANIKYAM REDDY, SHAIK HUSSAIN, D.V.SRIKANTH, DR.M.SREENIVASA RAO,(2015)Experimental Analysis and Optimization of Process Parameters in Machining of RCFRP by AJM,International
Journal of Innovative Research in Science, Engineering and Technology, Vol. 4, Issue 8, 70857092.

[28] THOMAS BECK,(May 2011) Laser drilling in gas turbine blades, macro materials processing, No. 340-43.

[29] YENI MELIA, (2016), Multi Attribute Decision Making Using Simple Additive Weighting and Weighted Product in Investment,. International Academic Journal of Business Management Vol. 3, No. 7, 1-15.

[30] SHANKAR CHAKRABORTY, EDMUNDAS KAZIMIERAS ZAVADSKAS,(2014),Applications of WASPAS Method in Manufacturing Decision Making. INFORMATICA, Vol. 25, No. 1, 120.

[31] E. K. ZAVADSKAS, Z. TURSKIS, J. ANTUCHEVICIENE,

A.ZAKAREVICIUS.(2012)Optimization of Weighted Aggregated Sum Product Assessment // Electronics and Electrical Engineering., Kaunas: Technological, No. 6 (122) ,3-6.

[32] ROBERT BOBBY, (2013) Nozzles: Selection and Sizing, Produced by Communications and Marketing College of Agriculture and Life Sciences, Virginia Polytechnic Institute and State University, Publication 442-032 1-12

[33] CHING-BEEN YANG \& CANG-GE LIN \& HSIU-LU CHIANG \& CHEIN-CHUNG CHEN,(2017)Single and multiobjective optimization of Inconel 718 nickel-based super alloy in the wire electrical discharge machining, Int $J$ Adv Manuf Techno 93,3075-3084

[34] ATUL SHUKLA, PANKAJ AGARWAL, R.S. RANA AND RAJESH PUROHIT, (2017), Applications of TOPSIS Algorithm on various Manufacturing Processes. A Review, Materials Today: Proceedings 4 .5320-5329.

[35] SRIKANTH D.V, M. SREENIVASA RAO (2014), Metal Removal and Kerfs Analysis in Abrasive jet drilling of Glass Sheets, Procedia Materials Science 61303 - 1311

[36] www.azom.com/article.aspx?ArticleID=9301

[37] MILOŠ MADIĆ, MIROSLAV RADOVANOVIĆ, DUŠAN PETKOVIĆ(2015),non-conventional machining processes selection using multi-objective optimization on the basis of ratio analysis method, Journal of Engineering Science and Technology Vol. 10, No.11.1441 - 1452. 